\title{
Insect Bite Hypersensitivity in Horses ${ }^{1}$
}

\author{
Rosanna Marsella, Nicky Craig, Carissa Wickens, and Samantha Brooks ${ }^{2}$
}

\section{What is allergic skin disease?}

Allergic skin disease is a very common cause of itching in horses, and arises from a combination of inherited traits and exposure to allergic triggers known as allergens. Allergens are substances that can trigger inappropriate immune responses, known as allergic reactions, in allergic individuals. In allergic skin disease, these allergic reactions manifest in the skin. In horses, they often cause itching, but in some cases they may produce lumps known as hives (or urticaria) without itching. Which allergens an allergic horse is allergic to depends on the individual horse. Potential allergens include various pollens, molds and grasses in the environment, food allergens, and/or insect bites. Allergies can be very challenging to control because most allergic horses are allergic to more than one allergen.

In itchy, allergic horses, exposure to allergens causes the skin to itch and become inflamed. Different allergens add up to make these effects worse. The horse responds by rubbing, scratching, and biting to try to relieve the itching, which causes the skin to become more damaged and inflamed, often with diffuse or patchy hair loss. The inflamed skin is vulnerable to secondary bacterial infections, which causes even more itching. Signs of inflammation and secondary bacterial infections of the skin include areas where the coat appears roughened or the hair has been lost. Some horses develop small lumps in the skin, crusts, scabs, reddened areas, or grey scales (skin flakes or dandruff) on the skin (see Figure 1). These lesions may become open sores as the horse rubs or chews at them. Allergies often affect the ears, face, mane, girth, groin, and tailhead areas in particular. In the ears, inflammation of the skin tends to lead to yeast overgrowth, which can also cause itching, and is visible as greyish color and flakes or scaling on the skin. The itching can severely affect the horse's quality of life, leading to the horse wounding itself by biting or scratching, and it can reduce the utility of the horse

\section{Managing Allergic Skin Disease}

The first and most important stage in addressing your horse's allergic skin disease is to consult your veterinarian to confirm that the horse has allergies and not another condition that looks similar. Once it is confirmed that your horse has allergic skin disease, your veterinarian will work with you to identify what allergens the horse is allergic to. Management primarily requires avoiding exposure of the horse to those allergens wherever possible, treating secondary infections, and managing the itching if allergen exposure is unavoidable.

For environmental allergies to pollens, molds and grasses, allergen immunotherapy shots can be formulated, which contain small amounts of allergen with which the horse is regularly injected. This works in the same way as hay-fever or allergy shots function in humans, and aims to "teach" the horse's immune system to tolerate the allergens instead

1. This document is AN359, one of a series of the Department of Animal Sciences, UF/IFAS Extension. Original publication date March 2020. Visit the EDIS website at https://edis.ifas.ufl.edu for the currently supported version of this publication.

2. Rosanna Marsella, professor, Department of Dermatology, University of Florida College of Veterinary Medicine; Nicky Craig, research scholar, Department of Dermatology, University of Florida College of Veterinary Medicine; Carissa Wickens, assistant professor, equine Extension specialist, Department of Animal Sciences; and Samantha Brooks, associate professor, Department of Animal Sciences; UF/IFAS Extension, Gainesville, FL 32611.

The use of trade names in this publication is solely for the purpose of providing specific information. UF/IFAS does not guarantee or warranty the products named, and references to them in this publication do not signify our approval to the exclusion of other products of suitable composition.

The Institute of Food and Agricultural Sciences (IFAS) is an Equal Opportunity Institution authorized to provide research, educational information and other services only to individuals and institutions that function with non-discrimination with respect to race, creed, color, religion, age, disability, sex, sexual orientation, marital status, national origin, political opinions or affiliations. For more information on obtaining other UF/IFAS Extension publications, contact your county's UF/IFAS Extension office. U.S. Department of Agriculture, UF/IFAS Extension Service, University of Florida, IFAS, Florida A \& M University Cooperative Extension Program, and Boards of County Commissioners Cooperating. Nick T. Place, dean for UF/IFAS Extension. 


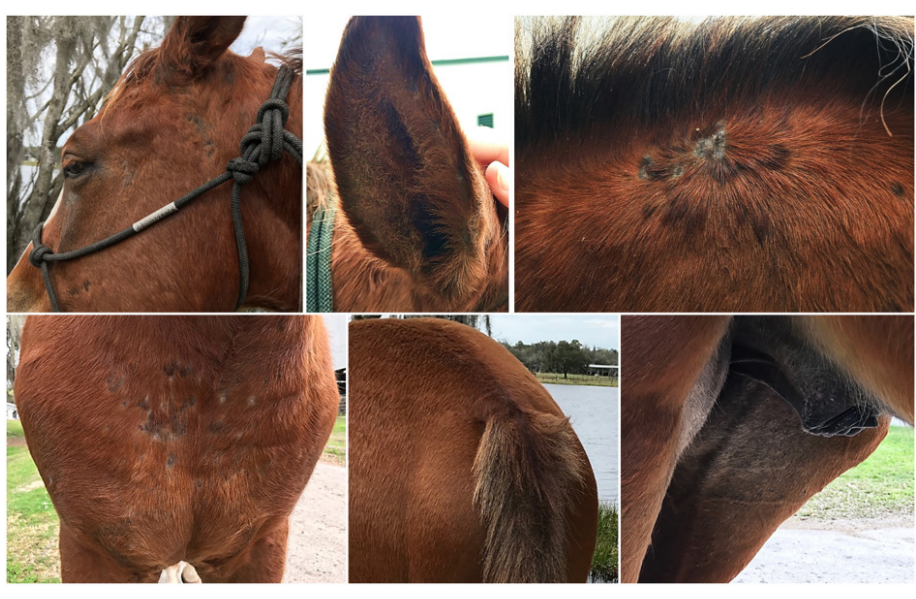

Figure 1. This itchy, allergic horse has patches of hair loss, scabs, and little lumps on his skin, all of which may indicate he is allergic to something. The areas affected suggest that he's allergic to insect bites possibly "no-see-ums," biting midges in the genus Culicoides, and may also be infected with parasitic nematodes in the genus Onchocerca. Areas of the horse's body particularly affected include the face, ears (where you can see tiny grey flakes of skin in the hair and the skin inside the ear is grey), chest, mane and tail (where you can see hair broken from rubbing), and groin areas. All of these are areas where these flies prefer to bite.

Credits: C. Wickens, UF/IFAS

of reacting to them. This is helpful in many horses, even though it can take up to a year to work, but it is not effective against insect bite hypersensitivity.

Insect bite hypersensitivity, an allergy to the bites of such insects as mosquitoes, biting flies, and Culicoides species (biting midges or "no-see-ums") is one of the most common allergies in horses, with Culicoides in particular being a major problem. The area of the horse affected, for example mane and tail, face or midline of the belly, will depend on which species of insect the horse is allergic to and where this species tends to bite.

\section{Managing Insect Bite Hypersensitivity}

1. Control the itching.

2. Treat secondary infections.

3. Prevent further bites using permethrin spray.

\section{Controlling The Itch}

Itching can be controlled using topically applied sprays, shampoos, or lotions containing anti-inflammatory medications such as hydrocortisone, triamcinolone, or fluocinolone acetonide. Lotions are particularly useful for the face and ears, which are not amenable to shampoo therapy. In severe cases, your veterinarian may prescribe stronger anti-inflammatory drugs such as prednisolone or dexamethasone.
Sensitivity or adverse reactions may occur after using any product on animals. If your horse shows increased itching and distress after you apply a product, bathe the horse with a mild, non-medicated shampoo, and rinse thoroughly with water. Consult your veterinarian immediately if signs continue.

\section{Treating Secondary Infections}

\section{Bacterial Infections}

Medicated shampoo baths that contain an antimicrobial ingredient, $2.5 \%$ benzoyl peroxide or $4 \%$ chlorhexidine, can be used to treat mild secondary bacterial skin infections (some $4 \%$ chlorhexidine shampoos also contain $1 \%$ hydrocortisone to reduce inflammation). Benzoyl peroxide is effective in removing crusts, but it may dry and bleach the coat in some animals. Shampoos containing ethyl lactate are also effective and appear to be gentler and less drying than other antimicrobial products. For small areas, topical antimicrobial sprays, such as oxychlorine- or ETDA-based products or $0.4 \%$ stannous fluoride, are available for use in horses.

How to use a medicated shampoo:

1. Groom horses before treatment to remove dirt and dust.

2. Wet the horse thoroughly.

3. Massage the shampoo gently into the coat.

4. Leave the shampoo on for $\mathbf{1 0 ~ m i n u t e s}$ to allow it to work.

5. Rinse the horse thoroughly.

Bathe the horse twice per week for 2 to 3 weeks until the coat no longer has sores, crusting or scale patches.

Where necessary, your veterinarian may also prescribe an oral antibiotic such as trimethoprim sulphate. However, bacterial resistance is increasingly common and other bacterial infections may be present, so if treatment does not result in complete resolution of the infection, then samples should be sent for bacterial identification and antibiotic sensitivity testing before deciding on further treatment. Always complete the full course of treatment as directed by your veterinarian: your horse may look better before the infection is completely resolved, and symptoms may return if you stop treatment prematurely. (If you see any unexpected or adverse effects from a medication contact your veterinarian for advice.) 


\section{Onchocerca Larvae}

In addition to causing allergic itching, Culicoides species also transmit larvae of the Onchocerca, which migrate through the skin, causing further itching and crusting.

Treat the horse with ivermectin as directed according to its body weight, every 2 weeks for 6 weeks (i.e., 3 treatments, 2 weeks apart) to clear the larvae. Alternatively, a single treatment with moxidectin can be used as directed according to body weight. Some horses react strongly to the death of the larvae and develop areas of swelling 1 to 3 days following treatment. This reaction should resolve on its own in 7 to 10 days.

\section{Treating Yeast Overgrowth in the Ears}

Scale in the horse's ears suggests yeast overgrowth following allergic inflammation. This can be treated using clotrimazole (e.g., Lotrimin) or miconazole cream applied to the scaling areas in the ears daily for 1 to 2 weeks. Do not use other antifungal creams unless recommended by your veterinarian. Some are not safe to use in ears.

\section{Preventing Culicoides Bites}

\section{Use Repellent}

Once a day and after bathing or heavy rain, administer $1 \%$ permethrin spray. Permethrin can be bought as a $10 \%$ solution and diluted 1:10 in water (1/10 quart of $10 \%$ permethrin added to $9 / 10$ quart of water) to produce a $1 \%$ solution. DO NOT USE 10\% SOLUTION UNDILUTED! Read and follow the product's instructions and warnings. Groom horses before treatment to remove dirt and dust, then apply the spray to the whole horse, paying special attention to legs, belly, shoulders, neck, and face. A cloth or wipe should be used to apply the spray carefully on the face to avoid getting the spray near the horse's eyes or mucous membranes (inside the nostrils and lips). Follow label instructions to protect yourself from exposure to the product when treating.

\section{Permethrin Warnings:}

- Permethrin is very toxic to cats. Do not allow cats to come into contact with permethrin products or treated horses while the permethrin is still wet.

- Wash hands after handling Permethrin.

- Permethrin is very toxic to aquatic organisms. Do not dispose of permethrin products into or near aquatic environments or drains.

If your veterinarian feels it is appropriate, dexamethasone can be added to the spray for up to a week to control itching. Wear gloves when handling dexamethasone spray, and protect yourself from exposure.
Where the face and ears are affected Equi-Spot ${ }^{\oplus}$ spot-on permethrin treatment can be used on the poll area every 2 weeks to protect this area.

As an alternative to permethrin, neem oil repellent sprays (e.g., Equiderma fly spray) are also effective in repelling biting midges. These should also be used daily and after bathing or heavy rain.

Other insecticides such as pyrethrins do not repel Culicoides (biting midges, or "no-see-ums) and will be ineffective in preventing allergies due to Culicoides bites.

\section{Avoid Exposure}

Culicoides midges breed in standing water, so keep the horse in dryer areas away from lakes, pools or puddles if possible. Biting midges are active from dusk until dawn, so keeping the horse in a stable at these times may reduce exposure to bites. If possible, use fans to prevent midges from flying into the stable. Mosquito Magnet ${ }^{\circledR}$ traps can also be used to reduce biting midges in the environment and can be effective over an area of up to one acre.

\section{Take-Home Message}

Itching in horses can be caused by many different problems that can be difficult to identify, diagnose, and manage. Always work with your veterinarian to get the correct diagnosis and the latest management advice. Currently, the most effective treatment for insect bite hypersensitivity is to prevent insect bites by using repellent.

\section{Additional Resources}

Mueller, R. S., E. Jensen-Jarolim, F. Roth-Walter, E. Marti, J. Janda, A. A. Seida, and D. DeBoer. 2018. "Allergen Immunotherapy in People, Dogs, Cats and Horses - Differences, Similarities and Research Needs." Allergy 73: 1989-1999.

Marsella, R. 2013. "Equine allergy therapy: update on the treatment of environmental, insect bite hypersensitivity, and food allergies." Veterinary Clinics of North America: Equine Practice 29(3): 551-557.

Schaffartzik, A., E. Hamza, J. Janda, R. Crameri, E. Marti, and C. Rhyner. 2012. "Equine Insect Bite Hypersensitivity: What Do We Know?" Veterinary Immunology and Immunopathology 147( 3-4): 113-126.

Scott, D., and W. Miller. 2011. Equine Dermatology. 2nd Edition. Philadelphia: Saunders. 
